\title{
THE INFLUENCE OF COMPUTER COMMUNICATION SKILLS ON PARTICIPATION IN A COMPUTER CONFERENCING COURSE*
}

\author{
JOHN A. ROSS \\ Ontario Institute for Studies in Education
}

\begin{abstract}
Computer-Mediated Communication (CMC) courses are attracting students with weak computer communication skills. This study examined what happened to these students when they enrolled in a CMC course that required high levels of peer interaction. It was anticipated that students with weaker skills would miss important instructional events, have lower levels of taskrelevant contributions, have less influence on group products, and engage in less demanding learning activities. But lack of technical skill had a marginal effect on participation, much less than prior knowledge of course content. The generalizability of this good news is limited by several contextual factors that supported participation of students with weak communication skills: student maturity, provision of a CMC coach, the ethos emerging from the structure and content of the course, and the low skill threshold required for participation.
\end{abstract}

The type of student enrolling in distance education courses delivered through computer conferencing is changing. The early courses, often focused on computer-related topics, attracted students with strong computer communication skills or interest in developing them. More recently a second group has become visible in CMC courses: a high need group with limited computer skills who seek help on even the most basic issues. The concern is that since CMC courses

*An earlier version of this article was presented at the annual meeting of the American Educational Research Association, New York, April 1996. The research was funded by the Social Sciences and Humanities Research Council of Canada. The views expressed in the article do not necessarily represent the views of the Council. Carole Crane contributed to the coding of students' computer communication skills. Pseudonyms are used for all students.

(C) 1996, Baywood Publishing Co., Inc. 
increase learner control and responsibility for the learning process, students with less developed computer communication skills may be disadvantaged.

\section{THEORETICAL FRAMEWORK}

Previous research has defined access to distance education as an admission/ retention issue [1]. But to participate in a CMC course students have to be able to communicate extensively with their peers and instructor [2-5]. To do so they need to master basic computer communication skills: how to create documents at their home computer, how to upload to the conference, how to download material, manage files, and so forth. Previous studies indicate that as $\mathrm{CMC}$ moves beyond the first wave of enthusiastic hackers they are attracting students who lack these skills. Foell found that students in a CMC course that attracted novice users had difficulty uploading and downloading files [6]. Anderson and Lee reported that students in a course using e-mail to supplement face-to-face interactions had problems using simple commands [7]. Ross, Crane, and Robertson (in press) uncovered an array of obstacles that impeded students access to CMC courses, including problems in connecting to the hub computer, using conferencing software, and managing files [27].

\section{Anticipated Impact of Weak Computer Communication Skills}

No previous study has examined the effects of weak computer communication skills on student participation in courses that demand high levels of interaction. Several predictions can be made.

First, students with weak computer communication skills may miss important instructional events. Novices take longer than experts to accomplish basic tasks and expend more energy in doing so. Their performance is slow and inefficient [8]. The pace may be too brisk for some when time lines are limited.

Second, students with weak computer communication skills may send fewer and shorter messages than students with stronger skills. Some messages may not reach the conference due to upload failures. Losing messages and having to resend them (or having to recreate them) may demoralize students. Repeated failure has a negative effect on beliefs about personal self-efficacy, which in turn leads to reduced goal setting and low task persistence $[9,10]$. Those who fail to reach the conference may make fewer attempts, plunging them into a downward spiral. Adept communicators are more likely to direct their messages to peers who are active in the discussion. Students with lesser skills might not feel included, especially if their contributions are rendered obsolete by more rapid responders, and could withdraw further. Novices attempting to participate in Internet conferences are sometimes met with open hostility and scolding, depressing their participation [11]. 
Third, students with weak computer communication skills may have less influence on group products. Deficiencies in communication skills are highly visible. Messages that arrive incomplete, garbled, or not at all, speak volumes about the competence of the sender. Recipients may extrapolate from the form in which the message arrives to its content, ascribing lower ability to the sender. Studies of small groups in face-to-face classrooms have found that overall student ability predicts the influence individual students have on the group product, resulting in a pattern of upper-ability dominance [12-14]. High ability students may also pick up the pace, pressuring less able students to complete tasks quickly $[15,16]$. CMC's narrow band width has a leveling effect. Social identifiers (gender, race, age, career stature) are muted, making it less likely that discussions will be dominated by high status individuals. But by diminishing the salience of these social identifiers, CMC delivery may increase the salience of computer communication skills, depressing the influence of students with less developed skills.

Fourth, a division of labor may arise in which students with weak CMC skills gravitate to tasks that are less demanding and less likely to lead to learning. Studies of small group work in face-to-face classrooms have found that lower ability students may participate as frequently as higher ability students but at lower depth. For example, less able students may carry out experiments while excluding themselves from writing tasks in which results are related to the concepts to be learned [17]. King found that low ability students, even when assigned leadership roles, focus on procedural rather than conceptual issues [18]. Such a division of labor has negative consequences for learning. It could arise in CMC courses if students with weak communication skills avoided productive learning tasks because their available energy had been drained by the difficulty of communicating or because the most productive learning tasks required communication skills they did not have.

\section{Alternate Explanations}

Differential participation in group deliberations may not be solely attributable to students' computer communication skills. Prior knowledge of the topic is likely to have a substantial impact. Students who have something to say are more likely to say it, producing more task relevant messages. McCreary and Van Duren found that graduate students participated more than undergraduates in open conferences [19]. What students say is more likely to be taken seriously if it is obvious they know what they are talking about. If there are grounds (from readings and the instructor) for judging the worth of individual contributions, students with prior knowledge will have more influence on group decisions. Students with prior knowledge are more likely to engage in high level conceptualization tasks because they bring to the course a framework for interpreting new information. 


\section{Research Questions}

1. What influence did students' communication skills have on their participation in a graduate course in which students worked in instructor-absent groups for a seven week period? It was anticipated that students with weaker communication skills would 1) miss instructional events, 2) have lower levels of taskrelevant contributions, 3) have less influence on group products, and 4) engage in less demanding learning activities.

2. How did the impact of weak communication skills compare to another factor that influences participation, prior knowledge of course content?

\section{METHOD}

\section{Sample}

Eleven men and four women, all practicing teachers, enrolled in a CMC course on cooperative learning. Four were doctoral candidates; the remainder were working toward master's degrees. In the first three and last two weeks of the course students interacted with the instructor and the rest of the class on an individual basis. During the intervening seven week period they worked in groups of three and four. Group membership was based on interest in particular approaches to cooperative learning. The approaches were: STAD/TGT (i.e., Student-Teams, Achievement-Divisions, and Teams-Games-Tournaments [20]), Jigsaw [e.g., 21], Group Investigation [22], and Tribes [23]. During the sevenweek period each group made a group presentation, responded to questions and criticisms from other groups, and critiqued the presentations of others. The groups were unsupervised. The instructor did not read any of the messages they exchanged until the course was over. Students received group feedback from the instructor on their final products only. (Individual feedback was given on other assignments.)

\section{Sources of Data and Procedures}

A research assistant not familiar with the hypotheses of the study ranked students' computer communication skills within groups, assigning first rank to the most able, second rank to the next most able, etc. Students were re-ranked within groups on their prior knowledge of cooperative learning. The instructor independently ranked all students using the same procedures. Two minor discrepancies were resolved through discussion. Rankings were based on evidence generated prior to the start of the small group activities: 1) Student descriptions of their teaching backgrounds and previous exposure to cooperative learning, the hardware and software they were using, and ratings of their proficiency and confidence in CMC skills on entry to the course. 2) Student messages sent to a conference branch dedicated to sharing technical problems and solutions. 
3) Records compiled by a CMC coach hired to help students through technical problems. Four of the fifteen students in the sample contacted the coach for a total of thirteen contacts. 4) Student messages sent prior to the start of the small groups to the main conference and to a personal chat branch. Examples of the placements are shown in Table 1.

Messages exchanged by students within their groups $(N=673)$ and group products were entered into ATLAS/ti, a qualitative data analysis program [24]. The software enables users to assign codes to text, create new codes during analysis, group codes in networks, and create SPSS files for quantitative analysis. The group tasks consisted of 1) identifying criteria for judging qualitative research (maximum 500 words), 2) a presentation outlining the theoretical foundations, key teacher decisions, and evidence of student impact of one cooperative learning approach (maximum 5000 words), 3) a response to feedback on the presentations from other groups (maximum 1500 words), and 4) comments on the presentations of four other groups (maximum 500 words each).

Table 1. Examples of Levels of Computer Conferencing Skills and Prior Knowledge of Cooperative Learning

\begin{tabular}{lll}
\hline Level & \multicolumn{1}{c}{ Computer Conferencing Skills } & \multicolumn{1}{c}{$\begin{array}{c}\text { Prior Knowledge of } \\
\text { Cooperative Learning }\end{array}$} \\
\hline 1 [low] & $\begin{array}{l}\text { 1st CMC course; contacted coach } \\
\text { seven times; slow to send 1st message } \\
\text { to conference; garbled or incomplete } \\
\text { messages }\end{array}$ & $\begin{array}{l}\text { No previous experience or } \\
\text { knowledge in cooperative } \\
\text { learning }\end{array}$ \\
2 & $\begin{array}{l}\text { 2nd CMC course; contacted coach } \\
\text { twice; ongoing problems with connec- } \\
\text { tions to the hub computer }\end{array}$ & $\begin{array}{l}\text { Attended a workshop on } \\
\text { one approach: Tribes }\end{array}$ \\
3 & $\begin{array}{l}\text { 2nd CMC course; offered advice on } \\
\text { how to upload and download to the } \\
\text { class }\end{array}$ & $\begin{array}{l}\text { Attended conferences on } \\
\text { cooperative learning and } \\
\text { has used Jigsaw } \\
\text { frequently. }\end{array}$ \\
& $\begin{array}{l}\text { 3rd CMC course; M.Ed. in Educational } \\
\text { Computer Applications; opened the } \\
\text { branch for his group; suggested } \\
\text { strategies in technical branch; included } \\
\text { graphics in messages }\end{array}$ & $\begin{array}{l}\text { Plàning Ed.D. thesis on } \\
\text { cooperative learning; } \\
\text { extensive use of Jigsaw } \\
\text { and STAD in own class; } \\
\text { offered workshops to } \\
\text { teachers on cooperative } \\
\text { learning }\end{array}$ \\
\hline
\end{tabular}


The data were coded using three category schemes. The first emerged from the data through a process of analytic induction. It concerned technical issues: 1) explicit problems (e.g., "I tried to connect on Monday and the scratchpad was acting up so I gave up after several failed attempts"), 2) implicit problems (e.g., a jumbled line of text), 3) explicit technical skill (e.g., giving accurate guidance on how to perform a procedure), and 4) implicit technical skill (e.g., sending a graphic). Technical issues were coded for frequency and duration (number of lines of text).

The second set, influence on group deliberations, involved three codes determined in advance. 1) Procedural leadership referred to students giving directives to others (e.g., assigning tasks). 2) Influence on final products referred to the number of lines in the final text attributable to each student. The contribution had to be substantive. For example, boiler plate language expressing how interesting the group found the previous presentation, usually added by the editor of the final draft, was not coded. Credit was given only to the first person who raised a particular idea included in the final text, even if other group members repeated it in subsequent messages. For example, Irene suggested that her group's response to another group's presentation should be critical of the Jigsaw method because when it is first implemented students are so preoccupied with their own minipresentations (from expert groups) they do not listen to what other children are saying. This suggestion was repeated by two other group members as they revised the group's critique. George suggested that the problem could be solved, perhaps by teaching interpersonal skills, or the problem might disappear with time. In the final text the issue was addressed in a short paragraph. Irene was credited with four lines for the original criticism; George was credited with three lines for the proposed solution; Jim was given no credit even though he repeated both ideas in various messages. 3) Rejected contributions referred to lines of messages expressing ideas that did not appear in the final text. For example, Helen suggested that Sally include in her section of the presentation a strategy for minimizing student competition. Helen provided a description of the strategy and a reference to a journal article. Katherine's subsequent draft of her section made no reference to Helen's suggestion and the final text did not include it. Helen's suggestion was coded as a rejected contribution.

The third set of categories was also determined in advance. Woodruff proposed that small groups be viewed as micro communities that use argument as a form of inquiry, developing shared knowledge through constructive conflict [25]. Woodruff proposed an argumentation hierarchy that was adapted for this study. Level 1 arguments consisted of building a set of collectively valid statements. Passages in which students expressed unelaborated agreement with a proposition were coded this way. For example, "I agree with the presenting group that STAD . . f focuses on individual morsels of information and that teacher workload must be heavy." Six subcodes were used for Level 1: agreeing or disagreeing with ideas put forth by one's own group, another group, or the course readings. 
Level 2 arguments in Woodruff's framework are elaborations of an idea by suggesting warrants, evidence, or ways to test the idea. For example, Jim responded to a team member's suggestion by providing evidence to support her claim.

My major concern with STAD/TGT is with its application in higher grade levels (previously mentioned by Irene). As a high school science teacher I really can't see using STAD/TGT very much. High school students need a little more than a superteam notation as a motivation to learn. The reward system is just not befitting a high school environment. High school students will perceive this strategy as a kids' game. I think that STAD/TGT would work best in the lower grades where belonging to a superteam has significance.

Again there were three subcodes for Level 2 arguments, distinguishing among elaborations of ideas offered by the student's own group, other groups, and course readings. Level 3 arguments (labeled "identifying misconceptions" in this study) note discrepancies between a proposed idea and conventional belief. For example, Tina challenged claims made in the Tribes group presentation.

In section ... I noted how the responsibility is transferred to the students to manage the tribes. Unfortunately, very little was explained how a teacher would do this. It just doesn't happen with students, they need guidance in order to know what to do in order to manage their groups.

There were Level 3 subcodes for own group, other groups, and course readings. In Level 4 of Woodruff's account an idea is challenged by presenting contrary evidence, thereby suggesting an alternative hypothesis. In this study, Level 4 arguments were treated as reconceptualizations in which the arguer generates another point of view and provides some evidence for it (or uses evidence previously provided). For example, a member of Dianne's team told a story to show that having friends in the same group contributes to group productivity. Betty offered a different interpretation:

I wonder if the group that is very productive is so because the group members are friends, or are they friends because they are productive. Or is it a process that through inclusion exercises, possibly conducted by you, or by themselves, they have grown into both the friendship and/or the productivity.

In the first level of analysis, the quotation matrix function of ATLAS/ti was used to compare each code for high and low communication skill students. In the second level of analysis, the mean frequencies and mean quotation lengths for each code were calculated and the results compared for high (ranked 3 or 4) and low (ranked 1 and 2) communication skill students. Differences between the two 
groups were expressed as effect sizes (the means for the lows were subtracted from the means for the highs and divided by the standard deviation of the lows), because significance tests would be meaningless for such a small sample. The same procedure was followed for prior knowledge of cooperative learning.

\section{RESULTS}

The first issue was whether students with weak computer conferencing skills had technical difficulties that led to missing instructional events. Virtually all students encountered technical problems. The most common involved difficulties in connecting to the host computer from home machines, especially for students who relied upon overloaded service providers such as the Electronic Village, a teacher network.

The type of problem that students worried about was related to their skill levels. For students with weak communication skills even trivial problems loomed large ("my printer ran out of ink so I was a little disabled"). Students using their home computer's DOS editor to compose messages for uploading lamented that they could not figure out how to get to their word processing program to use its word count and spell check facilities.

But these concerns paled in comparison with persistent difficulties in uploading and downloading, problems that inhibited access of less skilled students to group activities. Sometimes they lost messages they were sending ("This is my second reply. I just lost my other one when my screen filled up with garbage. I'll be briefer and less intelligent this time."). Receiving information could also be problematic ("I did a search earlier on cooperative learning . . . before I could download it all, the Village wiped out my mailbox"). Sometimes their messages "came out all disjointed on the screen even though originally ... it seemed to display OK." They were often unsure whether their messages were getting through. They persisted but often gave up "after several failed attempts."

Students with low CMC skills at times disappeared from the conference entirely, evoking concern of other team members when group decisions had to be made.

Irene have you heard from George or do we assume he is lost in cyberspace . . . [a day later:] no sign of George? I guess we have to assume his server is down and out for the count. Do you think we should submit [the] presentation without his OK?

Jim, I am baffled too. I am not sure if George was revising his section on the teacher etc. He had said that he was going to ... I hate to tamper in case he has it done. If we don't hear soon, we should maybe send [the instructor] a note explaining our delay. 
At times students with weak CMC skills advised the rest of the group to go on without them and then felt guilty about not holding up their end.

I couldn't send any messages for the past three days because my login with [the university] was all messed up. I feel so badly to have been no help at all these past few days. I am truly sorry. I am sure you've already sent questions in by now, but I'll go ahead and send my thoughts from earlier in the week just to make myself feel like I did something.

There were occasions when low CMC skill students were unable to do their share because they lacked technical skills such as how to use the Internet to locate documents for their topic.

Students with low CMC skills felt victimized by equipment that seemed to have a mind of its own ("sorry, I accidentally touched the mouse and this is what happened"). They rarely offered advice to other group members on technical matters and when they did the guidance was at times incorrect or unhelpful ("Read the manual. It might be something small.").

Although students with greater communication skills reported half as many technical problems (an average of 6.1 compared to 11.3 for students with weak skills), the main difference was in the nature of the problems then encountered. They were more likely to be concerned with higher level challenges such as how to send graphics or technical-political questions such as how First Nations teachers could gain access to the Village. They also wrestled with technical glitches that were beyond student control (e.g., a "talk" facility that disappeared from the hub computer). In most instances students with high computer communication skills were able to solve their own problems ("usually, I have problems downloading long passages, so I'll download each part separately"). Occasionally they reported experiments they were conducting to identify causes and solutions for technical problems.

Students with high CMC skills were sympathetic to group members encountering technical difficulties and offered assurances that minor blemishes (e.g., spelling errors) did not detract from the quality of the message. They frequently offered sympathy and advice and offered to help students avoid technical challenges that were beyond them. For example, all groups rotated the responsibility for compiling individual submissions into a group response. A student with low CMC skills expressed concern about how much time this was taking because she had to retype all the messages that had been submitted on the topic-she did not know how to manipulate them electronically prior to uploading the group's report. After explaining how to merge files, a more skilled colleague sympathized.

If you cannot do this, you should not be doing the uploading [of the group product to the rest of the class] because your way is much too much work!!!! 
Holy cow-no wonder you had so much difficulty with the major assignment. I tried to help you organize by sending everything in one collected piece, but I can see now that that did not do anything to help you. Sorry to hear that you had to do so much extra work.

In summary, lack of computer communication skills influenced students ability to access group discussions and impeded their ability to function as equal group members. There were a few occasions in which they missed instructional activities. They expressed anxiety and guilt about their computer skills.

The second issue was whether students with weaker CMC skills sent fewer and shorter messages. Table 2 displays the mean passage lengths of low and high CMC students. The first category is the sum of all productive contributions made by students, consisting of ideas that they proposed for the group products (regardless of whether or not they were accepted by the group), arguments that they presented to their peers, and managerial moves to guide the group through the tasks. The overall difference in contribution was negligible. Despite the technical difficulties they encountered, students with weak communication skills contributed as much as other group members.

The third indicator was whether students with weaker CMC skills had less influence on the final product. This was not the case. All teams followed similar procedures for assignments. The presentation of one cooperative learning method to the rest of the class was the central preoccupation. Teams began thinking about it as soon as their branch was established. Individuals suggested what the contents of the presentation might be. The group mulled the task over until a conceptual leader suggested a framework for presentation. In every group the first framework to appear was modified only slightly. Students' typical response to the plan was to volunteer to complete one particular section. After modest trading back and forth individuals wrote their sections independently, usually generating several drafts that were revised on the basis of additional materials acquired by the writer rather than through debate among team members. There

Table 2. Mean Passage Lengths of Low and High CMC Skill Students

\begin{tabular}{|c|c|c|c|c|}
\hline \multirow[b]{2}{*}{ Passage Category } & \multicolumn{2}{|c|}{$\begin{array}{l}\text { Low CMC Skill } \\
\qquad(N=8)\end{array}$} & \multicolumn{2}{|c|}{$\begin{array}{l}\text { High CMC Skill } \\
\quad(N=7)\end{array}$} \\
\hline & Means & $S D$ & Means & $S D$ \\
\hline All productive contributions & 590.75 & 402.12 & 561.57 & 166.66 \\
\hline All arguments & 81.00 & 87.22 & 52.43 & 40.80 \\
\hline Influence & 377.38 & 228.25 & 338.57 & 161.75 \\
\hline Rejected contributions & 98.25 & 80.78 & 125.00 & 127.17 \\
\hline Procedural leadership & 52.00 & 43.08 & 54.14 & 63.36 \\
\hline
\end{tabular}


was little discussion of each other's sections and the final edit was a simple assembly task.

All groups followed a similar process for responding to the presentations of others. At the beginning of the work period (i.e., when another team had uploaded their presentation to the conference) individuals sent messages about the cooperative learning approach and the other team's treatment of it. One person volunteered to coordinate production. This task rotated among team members. There were several instances in which a student who had previously coordinated production volunteered to do so again but withdrew when another student who had not done the task volunteered. There was more discussion of ideas when producing responses to the assignments of others, in part because students were more conscious of word length limitations. A conceptual leader (usually not the production coordinator) would emerge to suggest a structure for the response, listing themes or issues to be addressed. As shown in Table 2 students with weak computer communication skills were as likely as those with stronger skills to suggest a framework, volunteer for sections, identify materials, exercise procedural leadership, and complete their portions of the assignment.

The fourth indicator was whether students with weak computer communication skills avoided high level conceptual tasks. Table 2 shows that students with weak communication skills were more likely to engage in argument construction, the most productive form of small group learning. But the means for the two skill groups were virtually identical for the top three categories (elaborating ideas, identifying misconceptions, reconceptualizing issues). The difference was limited to the lowest category of argument, agreeing or disagreeing with an idea that had been put forward. For example:

Finally I must agree with George on his point of STAD/TGT having the potential for dittoitus. The time constraints and the effort required to implement this strategy make it very appealing to use the same materials year after year. Thus neglecting new curriculum, more relevant sources, and reflective practice.

\section{Competing Explanations for Differential Participation}

Differential participation in learning was partly related to students' computer communication skills. But other factors appeared to be more important. Table 3, which represents differences between groups as effect sizes, illustrates the strength of one factor. (A second factor, gender, will be addressed in a separate report.) Table 3 shows that differences between students with weak and strong computer communication skills were small when compared to the effect sizes for prior knowledge of cooperative learning.

Students who were using cooperative learning methods in their classrooms and/or had attended workshops on peer-learning approaches made a 
Table 3. Effects of Computer Communication Skill, Prior Knowledge of Cooperative Learning on Passage Lengths (Effects Sizes)

\begin{tabular}{lcc}
\hline & $\begin{array}{c}\text { Computer Communication } \\
\text { Skills Rank }\end{array}$ & $\begin{array}{c}\text { Cooperative Learning } \\
\text { Prior Knowledge Rank }\end{array}$ \\
\hline All productive contributions & -.07 & 1.05 \\
All arguments & -.33 & .63 \\
Influence & -.17 & .86 \\
Rejected contributions & .21 & 1.54 \\
Procedural leadership & .05 & 1.06 \\
\hline
\end{tabular}

${ }^{a}$ Positive effect sizes indicate higher means for high computer communication skill students.

${ }^{b}$ Positive effect sizes indicate higher means for high prior knowledge students.

greater overall contribution to group deliberations. They had more influence on the final product than students who had less prior knowledge, even though more knowledgeable students offered many more suggestions that did not make it into the final texts, and they were more likely to offer procedural guidance as the group went about its work. In three of the four groups, the conceptual leader, the student who usually developed the framework for the group product, was someone with higher prior knowledge. The exception was a group led by a doctoral student who was very knowledgeable about curriculum issues, even though she had done little reading on cooperative leaming prior to the course.

Students who were more knowledgeable on entry were more likely to engage in all forms of argument. The differences were especially noticeable in the upper level argument category, although there were comparatively few of these. For example, George tried to get Jim to reconsider his conception of intelligence.

\footnotetext{
Jim, perhaps the idea of "slow learner" is parallel to that of "intelligence" and to that of singular achievement in terms of constants as a measure of "learning," which may not have anything to do with the acquisition of knowledge. I realize I'm talking "ideals" here, not daily school pragmatics. I had a discussion with a math teacher the other day whose prime focus was basic skills and the right answer. We had no grounds on which to communicate. He could see no other definition of curriculum, seeing it only as a predefined constant. For me Jigsaw is just another methodology for encouraging learning "with" rather than against each other. Of course I am looking at this from the point of a high school teacher who basically thinks in terms of the primacy of process.
}

Almost all the examples of arguments that identified misconceptions (Level 3) or attempted to reconceptualize issues (Level 4) came from those with prior knowledge. The exceptions came from two doctoral students. 


\section{DISCUSSION}

The findings indicate that students' computer communication skills had only a modest impact on their participation in a CMC course. Students with less developed skills encountered serious difficulties, especially in transferring files to and from the hub computer, and these obstacles did reduce their ability to complete some tasks in a timely fashion. But the difficulties were resolved. Students with weak communication skills participated as well as students with stronger skills. They produced as many task relevant messages, exercised as much procedural leadership, were equally (in one instance more) likely to engage in argumentation, and engaged fully in the most demanding learning activities. Any impediments to participation arising from technical deficiencies were inconsequential compared to the impact of prior knowledge.

This is good news. The study found that students do not need to be hackers to participate in CMC courses. But there were four contextual factors operating in this study that might limit its generalizability. The first concerns enabling student characteristics. Enrollment was restricted to teachers seeking to upgrade their qualifications: They were highly motivated learners, interested in the content of the course, who brought sophisticated learning strategies to it. There may also have been some self-selection on the part of students (about a third) who lived close enough to the university to access a similar course offered in face-to-face mode. Whether high school students or undergraduates (the two largest sources of distance education enrollments) would be as persistent and as capable of acquiring new skills remains to be demonstrated. For example, younger students are less likely than older students to seek help when they need it [e.g. 26].

The second contextual factor was the availability of technical support. Students enrolled in this course had access to a CMC coach, a mature adult educator who could be contacted by telephone, fax, or e-mail. A previous study found that this coach (in collaboration with other technical specialists) was successful in solving most of the problems that students raised [27]. Other studies [e.g., 28] have noted the importance of having a help desk to support CMC courses, particularly when training manuals are inadequate, which they usually are [4, 29]. Although technical support was not required by all students it was essential to some.

The third contextual factor concerns the ethos of peer support emerging from the structure and content of the course. How to learn from peers was the end and the means. The materials students were reading emphasized the virtues of students giving and seeking appropriate help to one another, the benefits of peer discussion, and the negative effects of individualism. Learning activities were structured so that students had to work with one another: they were required to generate complex group products demanding a diverse array of abilities; they had substantial discretion about how to organize and complete the assignments, requiring consensus decision making; they were given a single group mark for each product (which was combined with grades received on individual 
assignments); they were obliged to ask each for help on the assignments before approaching the instructor. The ethos of mutual help made it socially acceptable for students with weak computer communication skills to approach their peers for help and it placed an obligation on those with stronger skills to intervene if help was needed, even if no formal request was made. Having students in the same group for seven weeks contributed to helpfulness norms because students are more likely to seek help when they are familiar with the skills and demeanor of potential help givers [e.g., 30].

Fourth, the level of computer communication skill demanded by the course was relatively low. The most difficult tasks (creating, merging, and uploading text files) were quite basic. Students needed to reach a low threshold and there was little need to go beyond it. In contrast in other CMC courses students might have to create integrated texts generated by different programs (e.g., integrating graphics, texts, and statistics) or use sophisticated engines for searching the Internet. In these courses the variance in CMC skills might be much larger and the hierarchy of students much steeper.

Directions for future research might examine what happens to students with weak computer communication skills in less supportive contexts. Of special interest are professional upgrading courses with large enrollments, individualized tasks, and competitive reward structures, factors that retard the development of peer helping behaviors. Studies in this direction suggest a quantitative approach to research, correlating CMC skills against measures of participation and achievement while controlling for moderating factors like prior knowledge. These large enrollment courses offer economies of scale [31] but the costs for less able students may be considerable.

CMC is likely to become the method of choice for the delivery of distance education because of its economic and pedagogical benefits. Widespread adoption of CMC will increase the number of students enrolling with weak computer communication skills. Research needs to focus on what happens to these students in various settings, shifting attention from access/retention concerns to participation issues. It is not enough to get students to CMC courses. We need to design treatments that will enable them to be successful, regardless of their computer communication skills. We may also need to devise valid criteria to deny enrollment to students who lack the training to benefit from the program.

\section{REFERENCES}

1. D. Garrison, Quality and Access in Distance Education: Theoretical Considerations, in Theoretical Principles of Distance Education, D. Keegan (ed.), Routledge, London, pp. 9-21,1993.

2. L. Harasim, Teaching and Learning On-Line: Issues in Computer-Mediated Graduate Courses, Canadian Journal for Education Communication, 16:2, 1987. 
3. S. Hiltz, Collaborative Learning: The Virtual Classroom Approach, Technological Horizons in Education Journal, 17:10, pp. 59-65, 1994.

4. G. Phillips, G. Santoro, and S. Kuehn, The Use of Computer-Mediated Communication in Training Students in Group Problem-Solving and Decision-Making Techniques, American Journal of Distance Education, 2:1, pp. 38-51, 1988.

5. R. Wells, Computer-Mediated Communication for Distance Education: An International Review of Design, Teaching, and Institutional Issues, American Center for the Study of Distance Education, University Park, Pennsylvania, 1993.

6. N. Foell, Using Computers to Provide Distance Leaming, The New Technology, paper presented at the annual meeting of the American Vocational Educational Research Association, Orlando, Florida, 1989.

7. J. Anderson and A. Lee, Literacy Teachers Learning a New Literacy: A Study of the Use of Electronic Mail in a Reading Education Class, Reading Research and Instruction, 34:3, pp. 222-238, 1995.

8. J. Anderson, Acquisition of Cognitive Skill, Psychological Review, 89, pp. 369-406, 1982.

9. A. Bandura, Social Foundations of Thought and Action: A Social Cognitive Theory, Prentice-Hall, Englewood Cliffs, New Jersey, 1986.

10. D. Schunk, Goal and Self-Evaluative Influences during Children's Mathematical Skill Acquisition, paper presented at the annual conference of the American Educational Research Association, San Francisco, April 1995.

11. M. Ryder and B. Wilson, From Local to Virtual Learning Environments: Making the Connection, paper presented at the annual meeting of the American Educational Research Association, San Francisco, April 1995.

12. E. Cohen and R. Lotan, Producing Equal-Status Interaction in the Heterogeneous Classroom, American Educational Research Journal, 32:1, pp. 99-120, 1995.

13. T. Good, M. McCaslin, and B. Reys, Investigating Work Groups to Promote Problem Solving in Mathematics, in Advances in Research on Teaching, Vol. 3, J. Brophy (ed.), JAI Press, Greenwich, Connecticut, 1992.

14. C. Mulryan, Student Passivity during Cooperative Small Groups in Mathematics, Journal of Educational Research, 85:5, pp. 261-273, 1992.

15. J. A. Ross and J. B. Cousins, Giving and Receiving Explanations in Cooperative Learning Groups, Alberta Journal of Educational Research, 41:1, pp. 103-121, 1995.

16. C. Mulryan, Fifth and Sixth Graders' Involvement and Participation in Cooperative Small Groups in Mathematics, Elementary School Journal, 95:4, pp. 297-310, 1995.

17. C. Anderson, Engagement in Explanation and Design in Middle School Science, paper presented at the annual meeting of the American Educational Research Association, New Orleans, April 1994.

18. A. King, High and Low Achievers' Perceptions and Cooperative Learning in Two Small Groups, Elementary School Journal, 93:4, pp. 399-416, 1993.

19. E. McCreary and J. Van Duran, Educational Applications of Computer Conferencing, Canadian Joumal of Educational Communications, 16:2, pp. 107-115, 1987.

20. R. Slavin, Cooperative Learning: Theory, Research, and Practice (2nd Edition), Prentice Hall, Englewood Cliffs, New Jersey, 1995. 
21. J. Clarke, Pieces of the Puzzle: The Jigsaw Methods, in Handbook of Cooperative Learning Methods, S. Sharan (ed.), Greenwood Press, Westport, Connecticut, pp. 34-50, 1994.

22. Y. Sharan and S. Sharan, Expanding Cooperative Learning through Group Investigation, Teachers College Press, New York, 1993.

23. J. Gibbs, Tribes: A Process for Social Development and Cooperative Learning, Center Source Publications, Santa Rosa, California, 1994.

24. T. Muhr, ATLAS/ti: Computer Aided Text Interpretation and Theory Building. Release 1.1E, Scientific Software Development, Berlin, 1995.

25. E. Woodruff, Investigating Collaborative Maieutics: An Examination of the Effects of Face-to-Face and Computer Networked Communication Mediums on Peer-Assisted Knowledge-Building, unpublished doctoral dissertation, University of Toronto, Toronto, 1995.

26. S. Nelson-Le Gall and S. Glor-Scheib, Academic Help-Seeking and Peer Relations in School, Contemporary Educational Psychology, 11, pp. 187-193, 1986.

27. J. A. Ross, C. A. Crane, and D. Robertson, Equity of Access to Computer-Mediated Distance Education, Journal of Distance Education, in press.

28. P. Butcher and J. Greenberg, Educational Computing at the Open University: The Second Decade, Education and Computing, 8:3, pp. 201-215, 1992.

29. L. Davie and P. Palmer, Computer-Teleconferencing for Advanced Distance Education, Canadian Journal of University Continuing Education, 10:2, pp. 56-66, 1985.

30. S. Nelson-Le Gall and R. Gumeran, Children's Perceptions of Helpers and Helper Motivation, Journal of Applied Developmental Psychology, 5, pp. 1-12, 1984.

31. T. Andrews, The Development and Application of a Framework for the Evaluation of Distance Education at the Secondary Level, unpublished doctoral dissertation, University of Toronto, Toronto, 1996.

Direct reprint requests to:

Dr. John A. Ross

Trent Valley Center

Box 719, 150 O'Carroll Avenue

Peterboroug, Ontario

Canada K9J 7A1 